\title{
Digital Technology: e-Content Development using Apple Technology
}

\author{
Noraida Haji Ali ${ }^{1}$ and Rabiatul Addawiyah Hanim Mohd Rosli ${ }^{* *}$ \\ ${ }^{1}$ School of Informatics and Applied Mathematics, Universiti Malaysia Terengganu, \\ Terengganu, Malaysia \\ ${ }^{2}$ e-Learning Unit, Centre for Academic Planning, Development and Quality, \\ Universiti Malaysia Terengganu, Terengganu, Malaysia \\ "hanim@umt.edu.my
}

Published online: 29 July 2019

To cite this article: Noraida Haji Ali and Rabiatul Addawiyah Hanim Mohd Rosli. 2019. Digital technology: e-Content development using Apple technology. Malaysian Journal of Distance Education 21(1): 83-94. https://doi.org/10.21315/mjde2019.21.1.5

To link to this article: https://doi.org/10.21315/mjde2019.21.1.5

\begin{abstract}
e-Content development is used to support e-learning enviroment in term of digital learning material. Many researchers defined e-learning as a method used to access educational materials from the internet. e-Learning create a multiple interaction within an instructor, learners and a content to serve a most convenient way for a learning process. e-Learning is a main component nowadays, especially in schools, universities and education center. Digital technology serves as a support to the teaching and learning process and has contributed to increased motivation, total engagement and create interactive participation among teachers and students in the learning activity. There are many technologies have been used recently in education. Nowadays, Web 2.0 technologies are used for content creation for learning and teaching in higher education, that carried out between March and May 2007 for e-learning content. Other technologies that we can use for content creation through Apple technology. Apple technology is now widely used globally and has designed its unique technology with a universal character and offers a more efficient method to support multiple teaching and learning activity. Many application in Apple technology that related to e-Learning such as iBooks Author apps can be used to create an interactive content, widely use for e-learning purpose. This paper discusses about how the iBooks can be used to develop interactive e-content in e-learning environment specifically in a higher education. Many features in iBooks Author such as keynote presentations, interactive images, interactive galleries, media, 3D images and a few more that can create an interactive content.
\end{abstract}

Keywords: e-learning, e-content, digital technology, iBooks, Apple technology

(C) Penerbit Universiti Sains Malaysia, 2019. This work is licensed under the terms of the Creative Commons Attribution (CC BY) (http://creativecommons.org/licenses/by/4.0/). 


\section{Introduction}

Generally, digital content has been developed as a teaching delivery material for student. Teaching delivery has used various approaches such as seminar based teaching, resource based learning, collaborative learning, constructivist approach, problem-based learning, enquiry-based learning, e-learning and so on. e-Learning is one of digital-based learning for teaching approaches. According to Saeed Rezaei Sharifabadi (2006), e-learning is defined as the use of the internet to access learning materials; to interact with the content, instructor, and other learners; and to obtain support during the learning process, in order to acquire knowledge, to construct personal meaning and to grow from the learning experience. Using e-learning as a method for education nowadays can create students creativity and responsibility in learning. Thus, can create good iniative for learners and instructor in making both way interaction during the learning processes. As mentioned by Bryan (2015), numerous teaching methods can lead learners how to use the technology tools found on varied technology devices, such as phones, e-books and microscopes; and encouraging learners to enjoy the chase for new knowledge or the thrill of discovery. Based on the previous findings, it is very important to decide a teaching delivery method during the learning process in order to gain learning outcomes which have a positive impact on both learners and instructors. Interactive learning is one of delivery methods that are widely used for educational and networking purposes for engaging student purposes as well.

Electronic technologies and network is a main requirement especially in a learning environment. According to (Kramer, 2000), the availability of electronic and web-enabling technologies has tremendous influence on the success of e-learning. This paper organised as follow: introduction in section 1, literature review in section 2, iBooks development using Apple technology will be discuss in section 3 , and finally conclusion of this work will be presented in section 4 . Therefore, the objective of this paper is to describes how the iBooks' features can be used to develop interactive e-content in e-learning environment. Many features in iBooks Author such as keynote presentations, interactive images, interactive galleries, media, $3 \mathrm{D}$ images and a few more that can create an interactive content. 


\section{Literature Review}

Technology and education are two related components needed to create successful learning process. Relationship between this components has been discussed among researchers in higher education field. According to previous researcher, digital technology as a tool to help manage some of these changes, and in particular, to use it as a transformative tool in teaching and learning (Crook and Light, 1999). Learning process are now rapidly changed. Learners are now have different expectations from the traditional mechanism to the most current technology to support their learning. Learning communities are more intrested in new mechanisms and technologies to accommodate learning process. Digital technologies have the potential to support and shape a pedagogy which is more active, participatory, personalised, flexible, and inclusive (Laurillard, 2008).

The term "technology" refers to combinations of a methods and tools we use to solve problems or achieve a goal. Technology are usually defined by using high-tech tools and gadgets, networking, and more. (Stommel 2014) has described the use of technology as a result of many innovations and technological advances we live in a "plugged in world" and a very symbiotic one as well. Whatever tools we use are depending on our goals setting. Technology is now become part of our routine needs. According to (Saxena, 2013), technology improves education to a great extent and it has now become a need for revolutionising education for the better.

Any method to be used to deliver e-learning are differ and to suits own environment and surrounding practices. This is supported with the statement by Homer-Dixon and Homer-Dixon (2002), and Feinstein, Vorhaus and Sabates (2008). Teaching and learning with technology can deepen both learners and educators skills and capable to produce more productive outcomes and interactive. Some researchers agreed of the positive outcomes by using the technology throught the learning process (Passerini and Granger, 2000; Hooper and Rieber, 1995; Barnes, Marateo and Ferris, 2007). 


\section{iBooks Development Process}

e-Learning is an example of collaboration between technology and digital components. Apple technology is one of the newest technology widely used in learning environment either in school or higher education.

Apple Inc. is now one of the giant companies in creating innovative electronic devices to fulfill the current technologies trend especially in educational field. There is various interesting tools to be explored by using Apple devices such as iPad, Mac, iPhone and so on. The Apple developer offers a complete set of technical resources, support, and access to its software in providing developers with everything they need to create innovative and interactive content for teaching and learning. Using Apple technology is totally different compared to other technologies available worldwide. Every educators and learners are now capable to learn differently. With just single click on any feutures on the iPad or Mac via Apple apps, we can switch common format of any physical material such as textbook, magazine, article to more interesting format (Apple Education, 2015).

iBooks is an e-book application by Apple Inc. which is customised for its own iOS and OS X operating systems and devices. Furthermore, users can create more interactive teaching material by adding videos, images, audio and interactive icons to make the material more interesting. Creativity can transform typical mode of learning and educating to more interesting and interactive way. iBooks Author has everything you need to create a greatlooking book-beyond the written word. Figure 1 shows the process flow for iBooks development. 


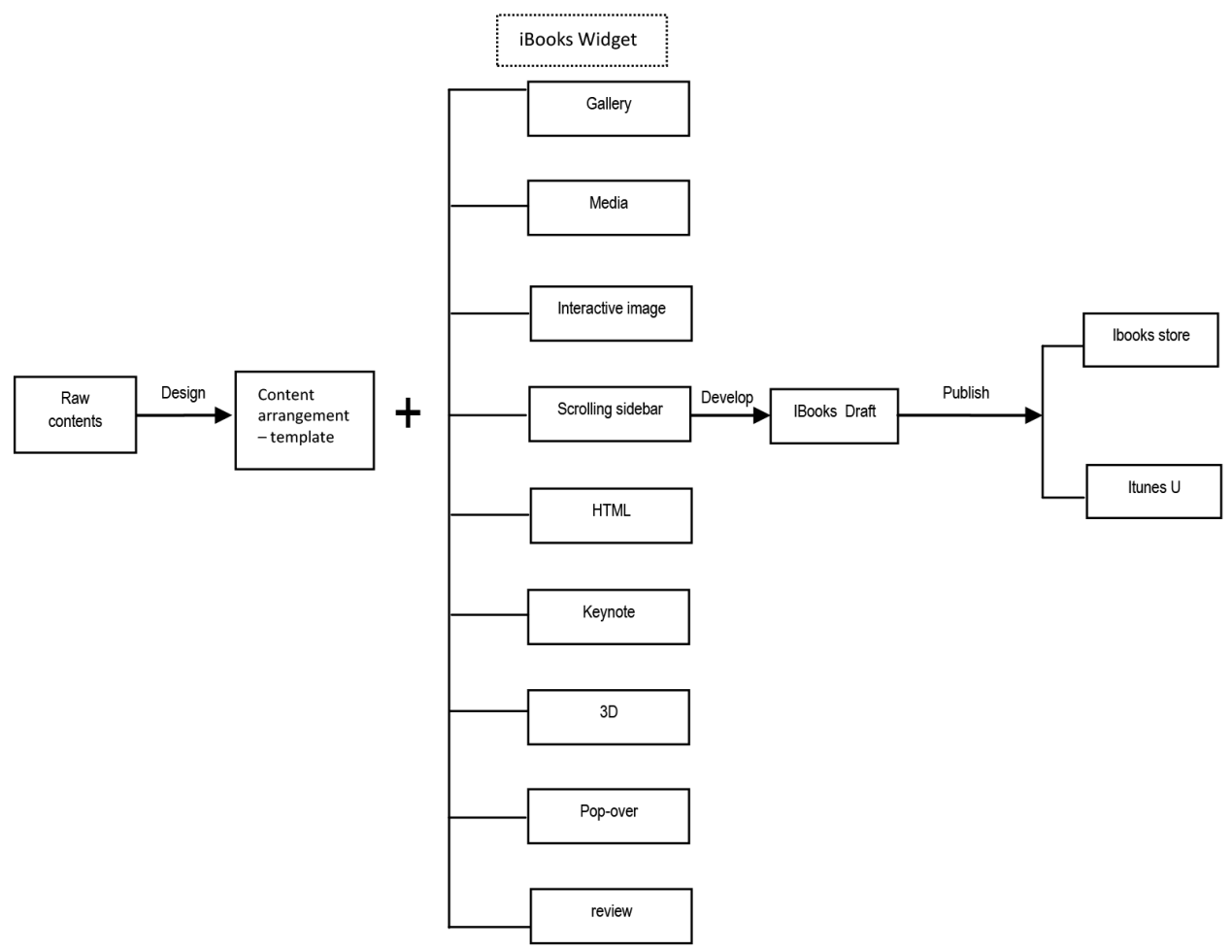

Figure 1 Process flow for development of iBooks

\section{iBooks Author}

Development of iBooks can be done using apps in Apple technology. iBooks Author is an apps that used to create an interactive books. This apps has designed with interactive widgets such as gallery, media, interactive image, scrolling bar, keynote and many others that highly supported for OS $\mathrm{X}$ Yosemite. Figure 2 shows the widget in iBooks Author.

Activities with the iBooks Author are consisted with dragging and dropping, customise with a click, add interesting widgets and even preparing an interactive assessment in the iBooks. We can start the design with a beautiful Apple-designed template. There are variety of styles, like classic textbook, cookbook or photo book, in both landscape and portrait orientations. According to Figure 2, there are eight widgets in iBooks Author. Widgets add multi-touch magic to books on iPad and Mac. These functions will bring the reader swipe-friendly photo galleries, animations that burst off 
the page, scrolling sidebars to linger over, pop-over widgets for an element of surprise, and engrossing 3D objects that are entertaining and interactive. And now, widgets can be set to play automatically, offering the readers a fun surprise when they turn the page. With iBooks Author, it's easy to create a book that's as much fun to explore as it is to read (iBook Author, 2016).

\section{Result and Discussion}

To implement the process of development of ibooks, here are the list of iBooks developed by Universiti Malaysia Terengganu:

(i) UMT's research magazines-Voyages of Discovery version 1

(ii) UMT's research magazines-Voyages of Discovery version 2

(iii) A New Invasive Coconut Pest in Terengganu: Rhynchophorus ferrugineus (Coleoptera: Curculionidae)

(iv) Basic field guide to microfungi

All these iBooks can be viewed through Apple devices such as iPad, iPhone, Macbook and so on. Figure 3 shows the iBooks developed by Universiti Malaysia Terengganu.



Figure 3 Example of iBooks 
Figure 4 shows the example for gallery widget. We can put a few images in one page, and readers can just swipe to change the images. We can touch to enlarge the images. Figure 5 shows the example of interactive media widget. We can provide detailed information about specific parts of a graphic using this widget. Readers can zoom in to enlarge the graphic, tap or click a label to view its complete description, and easily navigate from label to label.

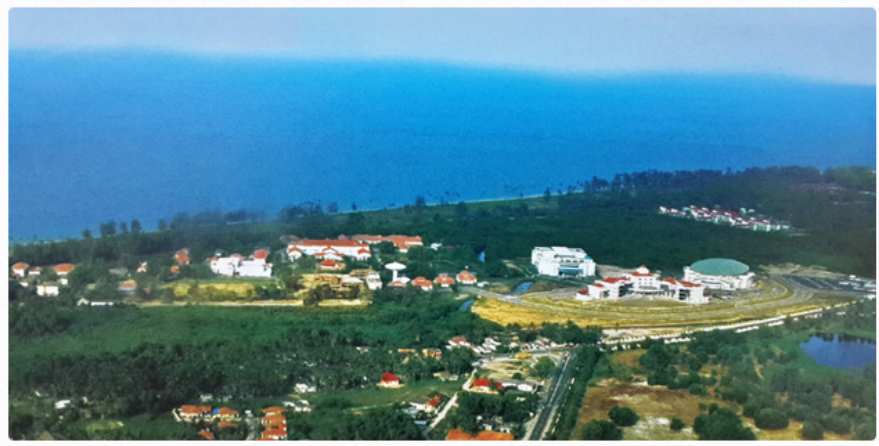

A bird's eye view of the UMT campus, with the Terengganu coast in the background.

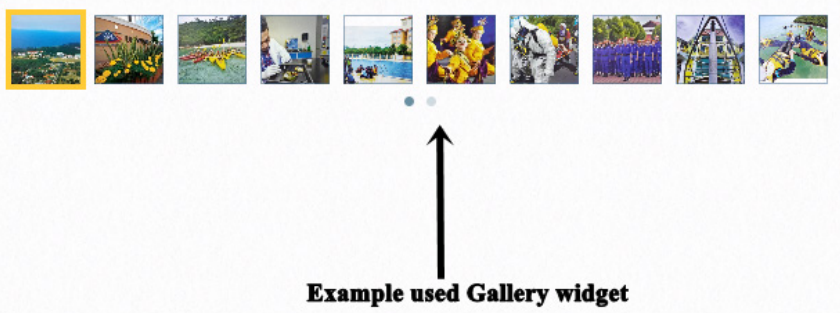

Figure 4 Gallery widget 


Library $\equiv$ Chapter 4: MARINE SCIENCE 目 淙 Q

\section{4 \\ MARINE SCIENCE EXCELLENCE}

INOS Spearheads

Sunda

Shelf Research

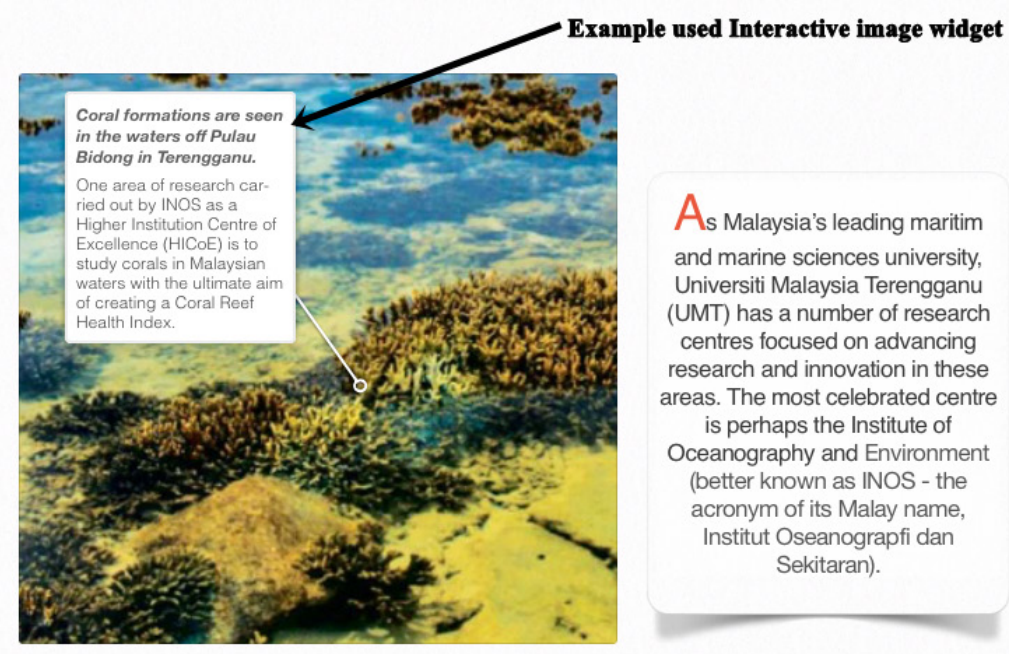

Originally known as the Marine Science Station at the Faculty of Fisheries and Marine Science at Universiti Pertanian Malaysia (UPM - Agriculture University of Malaysia), it was accorded official status following a recommendation by the Intergovernmental Oceanographic Commission of UNESCO. In July 2012, it

was recognised as Malaysia's 7th Higher Institutions Centre of Excellence (HICoE) in the field of Marine Science by the Ministry of Higher Education - an accolade which has strengthened its mission to become the knowledge leader of the South China Sea.

Figure 5 Interactive media widget

Figure 6 shows the example of media widget. We can add a video or audio in same page. This widget allow reader to play video or audio directly while reading the text. Figure 7 shows the example of Pop-Over widget. An overlay (with text, images, and shapes) that opens when the reader taps or clicks an image in the completed book. 


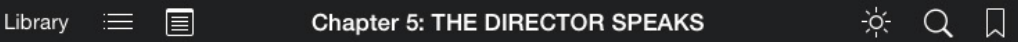

SEATRU was founded in 1993 by two UMT lecturers - Prof Dr Chan Eng Heng and Assoc Prof Liew Hock Chark - and its establishment was spurred by the shocking decline in the number of turtle eggs harvested by egg collectors. Whereas in the 1970s, turtle eggs would fill the brim of the collectors' boats, by the 1990s the amount collected had diminished two types of research as part of INOS being a HICoE - namely studying sea turtles at their foraging grounds in the Bay of Brunei, and also observing sea turtle hatchlings during their 'lost years'. These will help add to the understanding of these great marine creatures which are very much part of the natural heritage - not just Malaysia's but also the region as whole.

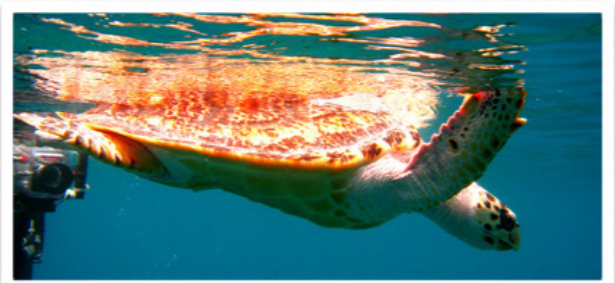

considerably. It was proof of one thing the sea turtles had to be protected.

In 2009, SEATRU was placed under the auspices of INOS. Speaking on that, Dr Juanita said, "It was a good decision because it has helped us a lot. In terms of research, being part of INOS has enabled us to tap into its resources and equipment. Furthermore, being part of INOS has helped us in funding, especially in view of it being a HICoE." SEATRU is conducting
In addition, SEATRU conducts turtle conservation activities in Pulau Redang (Redang Island) which is a nesting ground for both the Green Turtle and Hawksbill Turtle and set up a project site at Chagar Hutang beach in 1993. According to $\mathrm{Dr}$ Juanita, the SEATRU team perform long-term tagging and

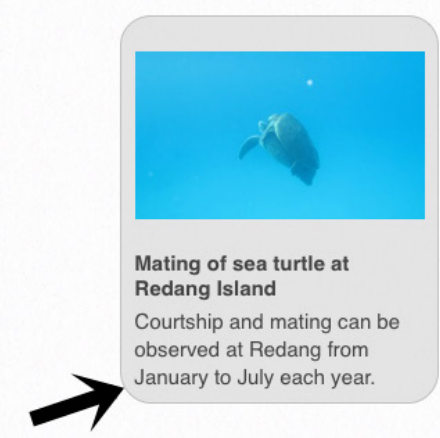

\section{Figure 6 Media widget}



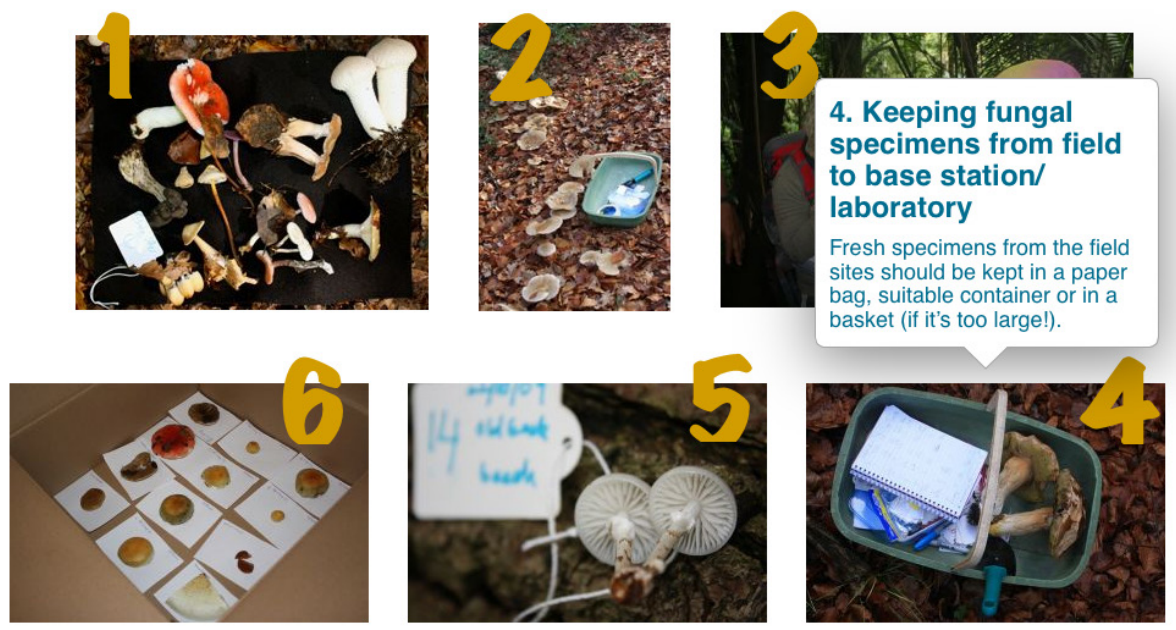

\section{Guidelines for Collecting \& Preserving Fungi}

Figure 7 Pop-over widget

\section{Conclusion}

This paper discusses about e-content development using Apple technology. iBooks Author is an amazing app that allows anyone to create beautiful iBooks textbooks. e-Content through iBooks can be used as a delivery method for e-learning specifically in a higher education environment. iBooks were develop to enhance the digital content in university which is align with university mission and vision. Apart from that, it is an initiative to bring out the brand of university locally and globally. Universiti Malaysia Terengganu (UMT) are now becoming the first public university in Malaysia to publish iBooks in iBooks store. The best thing about iBooks Author is that it is extremely easy to use. It contains templates for design layouts to help us while developing. We can add text and images by simply dragging and dropping and if you want to jazz up the e-book, simply by using the code in JavaScript and HTML, you can create interactive widgets to add 
videos, keynote presentations and interactive photo galleries. And, when the e-book is ready, the author can also preview the e-book using the iPad over a WiFi network before submitting it in the iBooks Store for approval. Before we can publish it to the iBooks Store, we need to do the a few step.

\section{Acknowledgements}

A special note of thanks to iBook's developer, PPDSNZ, UMT's top management and the reviewers for their great expert guidance.

\section{References}

Apple in Education. n.d. Available at https://www.apple.com/education/ (accessed 27 April 2015).

Barnes, K., R. C. Marateo and S. P. Ferris. 2007. Teaching and learning with the net generation. Innovate: Journal of Online Education 3(4): 1. Available at: http://nsuworks.nova.edu/innovate/vol3/iss4/1 (accessed 10 May 2015).

Bryan, V. C. 2015. Self-directed learning and technology. The Education Digest 80(6): 42-44.

Crook, C. and P. Light. 1999. Information technology and the culture of student learning. In Learning sites: Social and technological resources for learning, eds. J. Bliss, R. Saljo and P. Light, 183-193. New York: Pergamon.

Feinstein, L., J. Vorhaus and R. Sabates. 2008. Learning through life: Future challenges. London: The Government Office for Science. http://www.bis.gov.uk/assets/ biscore/corporate/migratedD/ec group/103-08-FO on (accessed 13 April 2015).

Homer-Dixon, T. F. and T. Homer-Dixon. 2002. The ingenuity gap: Facing the economic, environmental, and other challenges of an increasingly complex and unpredictable world. Vintage.

Hooper, S. and L. P. Rieber. 1995. Teaching with technology. In Teaching: Theory into practice, ed. A. C. Ornstein, 154-170. Needham Heights, MA: Allyn and Bacon.

iBook Author. http://www.apple.com/ibooks-author/ (accessed December 2016).

Kramer, B. J. 2000. Forming a federated virtual university through course broker middleware. Proceedings of LearnTec 2000, Heidelberg.

Laurillard, D. 2008. Digital technologies and their role in achieving our ambitions for education. London: Institute of Education, University of London. Available at http://eprints.ioe.ac.uk/628/1/Laurillard2008Digital_technologies.pdf (accessed 10 May 2015).

Passerini, K. and M. J. Granger. 2000. A developmental model for distance learning using the internet. Computers \& Education 34(1): 1-15.

Saeed Rezaei Sharifabadi. 2006. How digital libraries can support e-learning. The Electronic Library 24(3): 389-401. 
94 Malaysian Journal of Distance Education 21(1), 83-94 (2019)

Saxena S. 2013. Using technology in education: Does it improve anything? http://edtechreview.in/news/681-technology-in-education (accessed 27 April 2015).

Stommel, J. 2014. Critical digital pedagogy: a definition. Hybrid Pedagogy. http://www. hybridpedagogy.com/ (accessed 10 May 2015).

The future of teaching and learning in higher education. Available at https://www.rit.edu/ provost/sites/rit.edu.provost/files/future_of_teaching_and_learning_reportv13. pdf (accessed 13 April 2015). 